\title{
Prevalence and associated factors of late HIV diagnosis in north-western rural Tanzania: a cross sectional study
}

\author{
DANIEL W. GUNDA' ${ }^{\prime *}$, RASHID A. KAGANDA', FATMA A. BAKSHI', SEMVUA B. KILONZO' and BONAVENTURA \\ C. MPONDO 2 \\ 'Department of Medicine, Weill Bugando School of Medicine, P.O. Box 1464, Mwanza Tanzania \\ 2Department of Medicine, College of Health Sciences, University of Dodoma, P.O. Box 395 Dodoma, Tanzania
}

\begin{abstract}
Background: Despite scaling up of HIV and treatment services to improve the outcome of people living with HIV, still a high proportion of patients seek out medical attention at late stages of the disease. This contributes to late initiation of ART and poor clinical outcome especially in sub Saharan Africa. The literature on magnitude of this problem in Tanzania is still scarce. This study aimed to determine the prevalence and associated factors of delayed HIV diagnosis in rural Tanzania.

Methods: This was a cross sectional study, involving newly diagnosed adult HIV patients sent in for care and treatment linkage. Information regarding age, sex, WHO stage, type of opportunistic condition, HIV testing service and on diagnosis CD4 counts were all collected. On diagnosis CD 4 counts $<200$ cells/ $\mu$ l was coded as Late HIV diagnosis. The proportion of with Late HIV diagnosis was calculated and logistic regression modal was used to determine the degree of association of different variables at $95 \% \mathrm{Cl}$.

Results: In total 649 patients were included in this study. The median age of the study participants was 45.5 years most of them being females 396 (61.02\%). The median CD4 count was 168 cells/ $\mu$ l and majority of our study participants 468 (72.11\%) were in WHO clinical stage $3 \& 4$. Overall $385(59.32 \%)$ were found to have Late HIV diagnosis where $303(78.70 \%)$ had stage $3 \& 4$ AIDS defining illness $(O R=2.2, p<0.001)$. Male patients were predominantly affected $(O R=1.4, p=0.035)$, who were more likely to be tested following PITC service (OR=30, $\mathrm{p}<0.001)$.

Conclusions: Late HIV diagnosis is prevalent in our setting with high prevalence of most of the stage $3 \& 4$ AIDS defining illnesses. Male patients are predominantly affected as late presenters. There is a need to strengthen and extend the available Provider Initiated Testing and Counselling activities to primary health care level.
\end{abstract}

Keywords: HIV, AIDS, late diagnosis, Tanzania

\section{Introduction}

HIV is still an ongoing global problem. Since its discovery in 1981 almost 78 million people have been infected with HIV (amfAR 2014). By 2014 the World Health Organization (WHO) reported a total of about 36.9 million people to have been living with HIV/AIDS (WHO, 2015). Globally, Sub-Saharan Africa (SSA) is the most affected region harbouring about $71 \%$ of the worlds' burden of HIV/AIDS (WHO, 2015), of whom more than 1.4 million people are living in Tanzania (MoHSW, 2014).

When left untreated HIV progresses reducing the number and quality of functional CD4 positive cells, causing high morbidity and mortality from opportunistic infections (Brooks et al., 2009). Highly active antiretroviral therapy (HAART) reverses the effect of HIV/AIDS through sustained virological suppression reducing the viral load and allows CD4 cell recovery (Le et al., 2013). These effects are clinically important that CD4 recovery restores the body's ability to fight against opportunistic infections (OI) reducing the morbidity and mortality of People Living with HIV/AIDS (PLWHA) (Badri et al., 2004; Reniers et al., 2014). With this medical success there have been an ongoing worldwide scaling up of HIV/AIDS care and treatment services with a central goal to improve the outcome PLWHA and reduce the rate of new HIV infection (Montaner et al., 2014). As of 2015 more than 15 million of PLWHA had access to anti-retroviral therapy (ART) globally (UNAIDS, 2015), and in SSA the number of people who have access to HAART has substantially grown from 100,000 people in 2003 to more than 8 million by the end of 2011 (UNAIDS, 2012). By the end of 2013 Tanzania there were more than 1209 health facilities where people could access to

\footnotetext{
*Correspondence E-mail: daniel rev2002@yahoo.com
} 
HAART and more than $37 \%$ of people living with HIV/AIDS were on HAART contributing to $5 \%$ of all people starting on ART globally (MOHSW, 2014).

In the face of these efforts to improve the care of PLWHA, there are still a high proportion of individuals who seek out medical attention in later stages of the disease (Sabin et al., 2004; Fisher, 2008). Varying magnitudes of late HIV diagnosis have been reported across the world depending on the case definition used. Between $40 \%$ and $75 \%$ of newly diagnosed HIV patients are reported as having delayed HIV diagnosis in most studies from Africa (Kigozi et al., 2009; Abebe et al., 2014). This phenomenon contributes substantially to late ART initiation especially in Africa (Colebunders et al., 2005; Lawn et al., 2005) leading into high rates of mortality within a year of ART initiation (Lawn et al., 2008; Brinkhof et al., 2009). Several other studies have also indicated that this subgroup of patients has a poor immunological recovery on HAART with increased risk of both HIV and non HIV related events (Kaufmann et al., 2005; Moore \& Keruly, 2007). In the background of this information WHO therefore recommends early diagnosis and timely initiation of HAART before the HIV state is adversely advanced (García et al., 2004; Yeni et al., 2004). Evidences have now accumulated indicating that patients initiated on HAART at less advanced HIV parameters have a much far better outcome on ART (Hunt et al., 2003), as compared to those who start late on ART.

However, even with these facts, there is dearth of information on the magnitude of the problem in rural Tanzania. Moreover, there is still a lack of studies addressing the risk factors associated with this phenomenon and the potential intervention in our setting. This study was therefore carried out to assess the prevalence of late HIV diagnosis, associated risk factors and potential interventions among newly diagnosed HIV patients on point of linkage to care and treatment services in north-western Tanzania.

\section{Materials and Methods}

This was a cross sectional study which was conducted at Rubya Designated District hospital (DDH) care and treatment centre (CTC). Rubya is one of the largest district level hospitals in Kagera region with a bed capacity of more than 500. It serves both in and out patients with CTC activities as part of routine out patients activities which started a way back 2004. The CTC serves about 700 new patients a year and it currently has more than 7000 registered patients. The hospital provides testing and counselling services at Reproductive and Child Health $(\mathrm{RCH})$, outpatient department (OPD) and inpatient department (IPD). Patients who test positive for HIV from the hospital and in catchment health centres are usually sent for linkage to CTC. At linkage patients routinely undergo clinical and laboratory workups. The WHO clinical staging is done and the opportunistic diseases are recorded. They additionally get their $\mathrm{CD} 4$ counts done among other important laboratory investigations. Eligible patients are started on HAART for free and they are scheduled for continuous follow up.

This study involved all newly diagnosed adult patients who were sent in for linkage for care and treatment services between December 2014 and November 2015. Eligible patients were invited and were asked for a consent to participate in this study. A minimum sample size of 634 patients was calculated assuming $40 \%$ of newly diagnosed adult HIV patients had late HIV diagnosis (Mhozya et al., 2015), with an allowable error of 0.04 at $95 \% \mathrm{Cl}$. Patients were enrolled on routine clinic days and they were serially enrolled until the sample size was reached.

After informed consent the referral note to CTC was reviewed by the researchers. Patients underwent routine clinical and laboratory workup. All important clinical data were recorded in patients CTC files and patients were sent for CD4 testing at the hospital laboratory. Data of research interest were then extracted and recorded in a special tool including the age, sex, presence or absence of AIDS defining complaint on diagnosis, model of HIV testing and counselling service whether Voluntary Counselling and Testing (VCT), Prevention of Mother To Child 
Transmission (PMCT) or provider initiated testing and counselling (PITC), World Health Organization (WHO) clinical stage and on diagnosis CD4 count.

\section{Data analysis}

Data management was done using Epi Data 3.1 (CDC Atlanta, US) and analysis was done using STATA version 12 (College Station, Texas, US). The CD4 counts were stratified into 2 with a cut-off point of 200cells $/ \mu \mathrm{l}$. Accordingly patients with $\mathrm{CD} 4$ counts $<200 \mathrm{cell} s / \mu \mathrm{l}$ on diagnosis were coded as having Late HIV diagnosis as used in other studies (Crabtree-Ramirez et al., 2012; Beyene \& Beyene 2015; Mhozya, 2015). Continuous variables were expressed as means with interquartile range and categorical data were expressed as frequencies and percentages. The proportion of patients with late HIV diagnosis was calculated and where appropriate the odds of factors associated with late HIV diagnosis were computed with $95 \%$ confidence interval and in all our analyses the variables were said to be strongly associated with outcome of interest when $p<0.05$

\section{Ethical consideration}

The permission to conduct and publish the information from this study was sought from the Bugando Medical Centre/Catholic University of Health and Allied Sciences (BMC/CUHAS) joint ethical and research committee and Rubya DDH administration. All participants consented for the study. The patients' identifiers were not included to maintain confidentiality. Patients who did not consent were attended as per routine and were not included in the study.

\section{Results}

\section{The demographic and clinical characteristics of the study participants}

A total of 649 patients were included in this study. The median age of the study participants was 45.5 (22-71) years; most of them being females 396 (61.02\%). The median CD4 count was 168 (87257) cells/ $\mu$ l and majority, 468 (72.11\%) were in WHO clinical stage 3 and 4 . Most of the study participants, $569(87.67 \%)$ had their HIV testing following PITC service (Table 1).

Table 1: General clinical, demographic characteristics of the study participants

\begin{tabular}{lll}
\hline Factors & Response/Value & Median (IQR) or Number (\%) \\
\hline Age (years) & Median & $45.5[22-71]$ \\
& $\geq 50$ & $45.5[22-71]$ \\
Sex & $<50$ & $403(62.10)$ \\
WHO Stage & Male & $253(38.98)$ \\
& Female & $396(61.02)$ \\
Baseline CD4 counts (cells/ $\mu$ I) & 3 and 4 & $468(72.11)$ \\
& Median & $181(27.89$ \\
& $<200$ & $168(87-257)$ \\
& $200-350$ & $385(59.32)$ \\
HIV tested via & $>350$ & $213(32.82)$ \\
& PITC & $51(7.86)$ \\
& VCT & $569(87.67)$ \\
& PMCT & $56(8.63)$ \\
\hline
\end{tabular}

IQR: interquartile range; PITC: Provider initiated testing and counseling; PMCT: Prevention of mother to child transmission; VCT: voluntary counselling and testing; WHO: World Health Organization

Fever of more than a month was the most common clinical complaint (40.5\%). Other important conditions/diseases include Diarrhoea, Herpes zoster, pulmonary and extra pulmonary tuberculosis and pruritic popular eruption (Figure 1). 


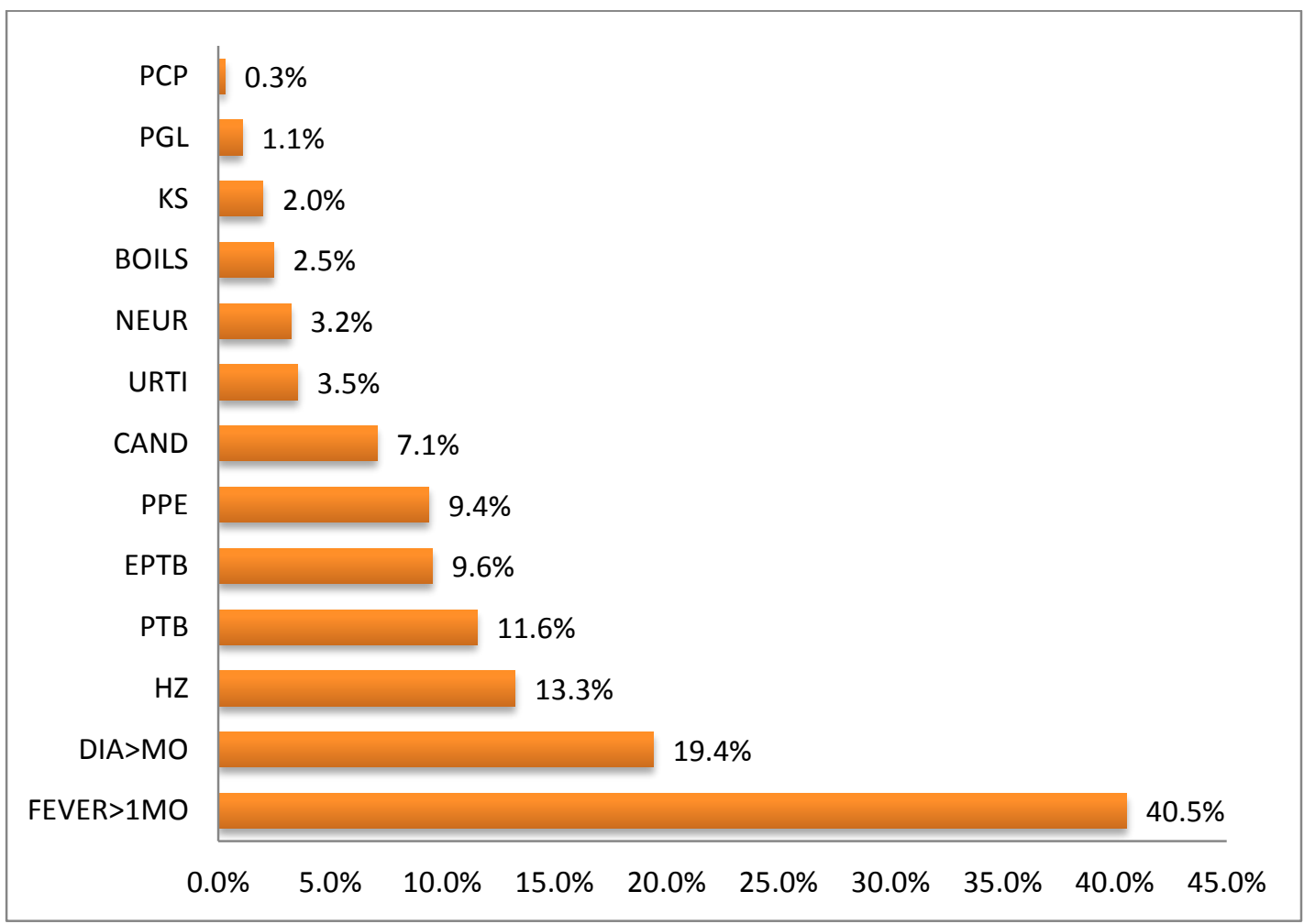

Figure 1: Distribution of opportunistic condition among study participants

DIA: Diarrhoea; EPTB: Extra pulmonary Tuberculosis; HZ: Herpes zoster; KS: Kaposi's sarcoma; OI: opportunistic infection; PCP: Pneumocystis carinii Pneumonia; PGL; Persistent generalized Lymphadenopathy; PPE: Pruritic papular eruption; NEUR: Neurological manifestations; PTB: Pulmonary TB; URTI: Upper Respiratory Infection

\section{Prevalence and associated factors of late HIV diagnosis}

In this study late HIV diagnosis was found in 385 (59.32\%) of patients who came for linkage to CTC services (Table 1). Late HIV diagnosed was found to be strongly associated with being male $(O R=1.4, p=0.035)$, being diagnosed through PITC $(O R=30, p<0.001)$ and having stage 3 and 4 AIDS defining illness $(\mathrm{OR}=2.2, \mathrm{p}<0.001)$ (Table 2$)$.

Table 2: Factors associated with late HIV diagnosis among study participants

\begin{tabular}{|c|c|c|c|c|}
\hline \multirow[t]{2}{*}{ Factors } & \multicolumn{2}{|c|}{ 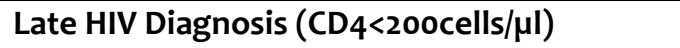 } & \multirow{2}{*}{$\mathrm{OR}(95 \% \mathrm{Cl})$} & \multirow[b]{2}{*}{ P-Value } \\
\hline & YES (N =385) & $\mathrm{NO}(\mathrm{N}=264)$ & & \\
\hline \multicolumn{5}{|c|}{ Age in years) } \\
\hline$\geq 50$ & $151(39.22)$ & $095(35.98)$ & & \\
\hline$<50$ & $234(60.78)$ & $169(64.02)$ & $1.15(0.8-1.6)$ & 0.404 \\
\hline \multicolumn{5}{|l|}{ Sex } \\
\hline Male & $163(42.34)$ & $090(34.09)$ & & \\
\hline Female & $222(57.66)$ & $174(65.91)$ & $1.4(1.02-1.96)$ & 0.035 \\
\hline \multicolumn{5}{|l|}{ WHO stage } \\
\hline 3 and 4 & $303(78.70)$ & $166(62.88)$ & $2.2(1.5-3.1)$ & $<0.001$ \\
\hline 1 and 2 & $082(21.30)$ & $098(37.12)$ & $0.5(0.3-0.6)$ & $<0.001$ \\
\hline \multicolumn{5}{|c|}{ HIV Testing via } \\
\hline PITC & $380(98.70)$ & $189(71.59)$ & $30(11.9-75.8)$ & $<0.001$ \\
\hline VCT & $002(00.52)$ & $054(20.45)$ & $0.02(0-0.04)$ & $<0.001$ \\
\hline PMCTC & $003(00.78)$ & $021(07.95)$ & $0.1(0.02-0.3)$ & $<0.001$ \\
\hline
\end{tabular}

PITC: Provider initiated testing and counseling; PMCT: Prevention of mother to child transmission; WHO: World Health Organization: VCT: voluntary counselling and testing 


\section{Discussion}

The objective of this study was to assess the magnitude of late HIV diagnosis, risk factors and discuss possible interventions among newly diagnosed adult HIV patients in western rural part of Tanzania. In this study about half of the study participants had a late HIV diagnosis. The prevalence of LHD in the index study is similar to a prevalence rate of 61\% reported in 2012 from Mexico (Crabtree-Ramirez et al., 2012). A lower prevalence rate of $40 \%$ was reported from a recent study done in eastern Tanzania (Mhozya et al., 2015). The difference in prevalence of LHD could partly be explained by the difference in study setting. The study in eastern Tanzania was done in an urban setting where probably people are more informed about HIV and have easier access to HIV testing as it has also been previously reported from Florida (Trepka et al., 2014). However even with these differences this suggests that in Tanzania, late presentation is encountered in both rural and urban settings. On the other hand a slightly higher prevalence were reported in 2014 in Nigeria (Agaba et al., 2014) and India (Bishnu et al., 2014)

Consistent with our findings male gender has been shown to be associated with late HIV diagnosis studies in Guinea (Nacher et al., 2005) and Nigeria (Agaba et al., 2014). This could partly be explained by the purported poor health seeking behaviour among male patients as it has also been reported previously (Nachega et al., 2006), potentially leading into late HIV diagnosis. Studies in China and Nigeria have indicated that male patients were 1.73 and 1.8 times more likely to present with late HIV diagnosis than female patients, respectively (Agaba et al., 2014; Jiang et al., 2015). Being linked to PMCT services studies suggest that female patients tend to be familiar with their HIV status much earlier and start on antiretroviral therapy promptly (Alibhai et al., 2010) as also suggested by the findings from this study.

Patients with late HIV diagnosis were also more likely to be associated with WHO stage 3 and 4 AIDS defining illnesses including, chronic diarrhoea, oesophageal and oral candidiasis and recurrent upper respiratory infection. Similarly previous studies have frequently shown that patients who are diagnosed with CD4 counts of less than 20ocells/ $\mu$ l have increased risk of associated fatal WHO clinical stage 3 and 4 AIDS defining conditions (Damtie et al., 2013; Kufa et al., 2014).

Although the proportion of patients who underwent HIV testing following VCT and PMCTC services was small, still most of them were diagnosed in less advanced HIV status suggesting that PITC services could be extended to reach healthier people at primary health care level. These observations are in agreement with findings reported from recent study from Ethiopia where patients who underwent HIV testing following PITC service were likely to have late HIV diagnosis as compared to testing following antenatal clinic (ANC) and VCT visits (Beyene \& Beyene, 2015). Similarly, a study assessing the role of PITC in enhancing early diagnosis and treatment of HIV concluded that PITC did not facilitate more timely diagnosis and early linkage to CTC for initiation of ART since most of their study participants also presented in WHO stage 3 and 4 defining illnesses as compared to VCT (Topp et al., 2012). Another study in Uganda also reported similar observations that, about two thirds of the patients who presented with late HIV diagnosis were diagnosed in medical inpatient department, whereby more than $27 \%$ of them had a prior attendance to medical clinic and about $30 \%$ had received treatment from pharmacy and drug stores before (Wanyenze et al., 2011), concluding that HIV testing in outpatient department could increase chances of earlier HIV diagnosis. Our findings are further more consistent with the conclusions drawn from a study in Zambia (Topp et al., 2011) suggesting that in order to increase the rate of early HIV diagnosis and timely initiation of HAART, the available PITC services should be intensified and expanded to include patients at primary health care level.

The findings from this study are clinically very important in our setting. It has widely been shown that patients with late HIV diagnosis stand a higher risk of morbidity and mortality influenced by opportunistic infections among others. In Taiwan, Fang et al. (2007) indicated that newly diagnosed HIV patients with low CD4 counts bellow 200cells/ $\mu$ l had a significant reduction 
of their life expectance at 5 years as compared to those with higher CD4 than 200cells/ $\mu$ l. Another study in India indicated that patients with CD4 <200cells/ $\mu$ l were six times more likely to develop

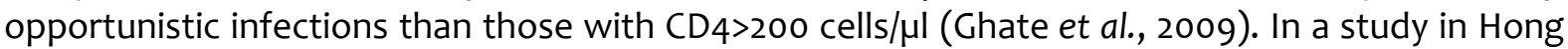
Kong, revealed that the burden of $\mathrm{OI}$ was much higher among those patients with advanced immune suppression (Wong et al., 2004). Similar findings were reported in a Cote d'Ivoire (DeufficBurban et al., 2007). This study had a number of limitations. The study being a cross-sectional, the fate of the late HIV diagnosis could not be assessed. In this study also the time from HIV diagnosis to ART initiation was not assessed.

In conclusion this study shows that the proportion of Late HIV diagnosis is significantly high in western rural Tanzania despite free access to HIV testing and counseling. Most of these patients underwent testing initiated by service provider (PITC), while already having AIDS defining illnesses. Male patients were mostly affected. This subgroup of patients is at high risk of poor outcome on ART. Strategies should be sought to increase HIV diagnosis at its earliest stage to improve the outcome of PLWHA in rural Tanzania, including strengthening and extension of the available PITC to primary health care and to incorporate male partner into PMCT services.

\section{Acknowledgements}

Authors would like to acknowledge and appreciate the assistance offered by the administrative and CTC staff members at Rubya Designated hospital.

\section{Competing interest}

Authors declare to have had no competing interest.

\section{Authors' contribution}

DWG: Conceived the idea and designed the study, acquired the data, analyzed the data and did the manuscript drafting. RAK: assisted designing the study; acquired the data and reviewed the manuscript for its intellectual content. FAT: assisted literature search and reviewed the manuscript for intellectual content SBK: Aided data analysis and reviewed the manuscript for intellectual content. BCM: Aided data analysis and review of the manuscript for its intellectual content. 


\section{References}

Abebe, N., Asfaw, T. \& Abajobir, A.A. (2014) Survival stataus of HIV positive adults on antiretroviral treatment in Debre Markos Referral Hospital, northwest Ethiopia: retrospective cohort study. Pan African Medical Journal 17: 88

Agaba, P.A., Meloni, S.T., Sule, H.M., Agbaji, O.O., Ekeh, P.N., Job, G.C., Nyango, N., Ugoagwu, P.O., Imade, G.E., Idoko, J.A. \& Kanki, P.J. (2014) Patients who present late to HIV care and associated risk factors in Nigeria. HIV Medicine 15: 396-405.

Alibhai, A., Kipp, W., Saunders, L.D., Senthiselvan, A., Kaler, A., Houston, S>, Konde-Lule, J., OkechOjony, J. \& Rubaale, T. (2010) Gender-related mortality for HIV-infected patients on highly active antiretroviral therapy (HAART) in rural Uganda. International Journal of Women's Health 2: 45-52.

amfAR (2014) World AIDS Statistics. The Foundation of AIDS

Badri, M., Bekker, L.G., Orrell, C., Pitt, J., Cilliers, F. \& Wood, R. (2004) Initiating highly active antiretroviral therapy in Sub-Saharan Africa: an assessment of the revised World Health Organization scaling-up guidelines. AIDS 18: 1159-1168.

Beyene, M.B. \& Beyene, H.B. (2015) Predictors of late HIV diagnosis among adult people living with HIV/AIDS who undertake an initial CD4 T-cell evaluation, northern Ethiopia: a case control study. PLoS One 10: e0140004.

Bishnu, S., Bandyopadhyay, D., Samui, S., Das, I., Mondal, P., Ghosh, P., Roy, D. \& Manna, S. (2014) Assessment of clinic-immunological profile of newly diagnosed HIV patients presenting to a teaching hospital of eastern India. Indian Journal of Medical Research 139: 903-912.

Brinkhof, M.W., Boulle, A., Weigel, R., Messou, E., Mathers, C., Orrell, C., Dabis, F., Pascoe, M. \& Egger, M. (2009) Mortality of HIV-infected patients starting antiretroviral therapy in SubSaharan Africa: comparison with HIV-unrelated mortality. PLoS Medicine 6: e1000066.

Brooks, J.T., Kaplan, J.E., Holmes, K.K., Benson, C., Pau, A. \& Masur, H. (2009) HIV-associated opportunistic infection-going, going, but not gone: the continued need for prevention and treatment guidelines. Clinical Infectious Diseases 48: 609-611.

Colebunders, R., Ronald, A., Katabira, E. \& Sande, M. (2005) Rolling out antiretrovirals in Africa: there are still challenges ahead. Clinical Infectious Diseases 41:386-389.

Crabtree-Ramirez, B., Caro-Vega, Y., Belaunzaran-Zamudio, F. \& Sierra-Madero, J. (2012) High prevalence of late diagnosis of HIV in Mexico during the HAART era. Salud Publica de Mexico 54: 506-514.

Damtie, D., Yismaw, G., Woldeyohannes, D. \& Anagaw, B. (2013) Common opportunistic infections and their $\mathrm{CD} 4$ cell correlates among HIV-infected patients attending at antiretroviral therapy clinic of Gondar University Hospital, Northwest Ethiopia. BMC Research Notes 6: 534 .

Deuffic-Burban, S., Losina, E., Wang, B., Gabillard, D., Messou, E>, Divi, N., Freedberg, K.A., Anglaret, X. \& Yazdanpanah, Y. (2007) Estimates of opportunistic infection incidence or death within specific CD4 strata in HIV-infected patients in Abidjan, Cote d'Ivoire: impact of alternative methods of CD4 count modelling. European Journal of Epidemiology 22: 738744 .

Fang, C.T., Chang, Y.Y., Hsu, H.M., Twu, S.J., Chen, K.T., Lin, C.C., Huang, L.Y., Chen, M.Y., Hwang, J.S., Wang, J.D. \& Chuang, C.Y. (2007) Life expectancy of patients with newly diagnosed HIV infection in the era of highly active antiretroviral therapy. Quarterly Journal of Medicine 100: 97-105.

Fisher, M. (2008) Late diagnosis of HIV infection: major consequences and missed opportunities. Current Opinions in Infectious Diseases 21: 1-3 
García, F., de Lazzari, E., Plana, M., Castro, P., Mestre, G., Nomdedeu, M., Fumero, E., Martinez, E., Mallolas, J., Blanco, J.L., Miro, J.M., Pumarola, T., Gallart, T. \& Gatell, J.M. (2004) T-cell response to highly active antiretroviral therapy according to baseline $C D+T$-cell count. Journal of Acquired Immune Deficiency Syndrome 36: 702-713

Ghate, M., Deshpande, S., Tripathy, S., Nene, M., Gedam, P., Godbole, S., Thakar, M., Risbud, A., Bollinger, R. \& Mehendale, S. (2009) Incidence of common opportunistic infections in HIVinfected individuals in Pune, India: analysis by state of immunosuppression represented by CD4 counts. International Journal of Infectious Diseases 13: e1-8.

Hunt, P.W., Deeks, S.G., Rodriguez, B., Valdez, H., Shade, S.B., Abrams, D.I., Kitahata, M.M., Krone, M., Neilands, T.B., Brand, R.J., Lederman, M.M. \& Martin, J.N. (2003) Continued CD4 cell count inceases in HIV-infected adults experiencing 4 years of viral suppression on antiretroviral therapy. AIDS 17: 1907-1915.

Jiang, H., Yin, J., Fan, Y., Liu, J., Zhang, Z, Liu, L. \& Nie, S. (2015) Gender difference in advanced HIV disease and late presentation according to European consensus definition. Scientific Reports 5: 14543.

Kaufmann, G.R., Furrer, H., Ledergerber, B., Perrin, L., Opravil, M., Vernazza, P., Cavassini, M., Bernasconi, E., Rickenback, M., Hirschel, B. \& Battegay, M. (2005) Characteristics, determinants, and clinical relevance of CD4 T-cell recovery sto $<500$ cells/microL in HIV type 1 infected individuals receiving potent antiretroviral therapy. Clinical Infectious Diseases 41: 361-372.

Kigozi, I.M., Dobkin, L.M., Martini, J.N., Geng, E.H., Muyindike, W., Emenyonu, N.I., Bangsberg, D.R. \& Hahn, J.A. (2009) Late-disease stage at presentation to an HIV clinic in the era of free antiretroviral therapy in Sub-Saharan Africa. Journal of Acquired Immune Deficiency Syndrome 52: 280-289.

Kufa, T., Mabuto, T., Muchiri, E., Charalambous, S., Rosillon, D., Churchyard, G. \& Harris, R.C. (2014) Incidence of HIV-associated tuberculosis among individuals taking combination antiretroviral therapy: a systematic review and meta-analysis. PLoS One 9: e11209.

Lawn, S.D., Harries, A.D., Anglaret, X., Myer, L \& Wood, R. (2008) Early mortality among adults accessing antiretroviral treatment programmes in Sub-Saharan Africa. AIDS 22: 1897-1908.

Lawn, S.D., Myer, L., Orrell, C., Bekker, L.G. \& Wood, R. (2005) Early mortality among adults accessing a community-based antiretroviral service in South Africa: implications for programme design. AIDS 19: 2141-2148.

Le, T., Wright, E.J., Smith, D.M., He, W., Catano, G., Okulicz, J.G., Young, J.A., Clark, R.A., Richman, D.D., Little, S.J. \& Ahuja, S.K. (2013) Enhanced CD4+ T-cell recovery with earlier HIV-1 antiretroviral therapy. New England Journal of Medicine 368: 218-230

Mhozya, H., Bintabara, D., Kibusi, S., Nelson, E. \& Mpondo, B.C. (2015) Late-stage disease at presentation to an HIV clinic in eastern Tanzania: a retrospective cross-sectional study. Malawi Medical Journal 27: 125-127.

MoHSW (2014) Global AIDS Response Country Progress Report. Dar es Salaam, Tanzania

Montaner, J.S., Lima, V.D., Harrigan, P.R., Lourenco, L., Yip, B., Nosyk, B., Wood, E., Kerr, T., Shannon, K., Moore, D., Hogg, R.S., Barrior, R., Gilbert, M., Krajen, M., Gustafson, R., Daly, P. \& Kendall, P. (2014) Expansion of HAART coverage is associated with sustained decreases in HIV/AIDS morbidity, mortality and HIV transmission: the "HIV treatment as prevention" experience in a Canadian setting. PLoS One 9: e87872. 
Moore, R.D. \& Keruly, J.C. (2007) CD4+ cell count 6 years after commencement of highly active antiretroviral therapy in persons with sustained virologicl suppression. Clinical Infectious Diseases 44: 441-446.

Nachega, J.B., Hislop, M., Dowdy, D.W., Lo, M., Omer, S.B., Regensberg, L., Chaisson, R.E. \& Maartens, G. (2006) Adherence to highly active antiretroviral therapy assessed by pharmacy claims predicts survival in HIV-infected South African adults. Journal of Acquired Immune Deficiency Syndrome 43: 78-84.

Nacher, M., El Guedj, M., Vaz, T., Nasser, V., Randrianjohany, A., Alvarez, F., Sobesky, M., Magnien, C. \& Couppié, P. (2005) Risk factors for late HIV diagnosis in French Guiana. AIDS 19: 727729.

Reniers, G., Slaymaker, E., Nakiyingi-Miiro, J., Nyamukapa, C., Crampin, A.C., Herbst, K., Urassa, M., Otieno, F., Gregson, S., Sewe, M., Michael, D., Lutalo, T., Hosegood, V., Kasamba, I., Price, A., Nakubalu, D., McLean, E. \& Zaba, B. (2014) Mortality trends in the era of antiretroviral therapy: evidence from the Network for Analysing longitudinal population based HIV/AIDS data on Africa (ALPHA). AIDS 28: S533-542.

Sabin, C.A., Smith, C.J., Gumley, H., Murphy, G., Lampe, F.C., Phillips, A.N., Prinz, B., Youle, M. \& Johnson, M.A. (2004) Late presenters in the era of highly active antiretroviral therapy: uptake of and responses to antiretroviral therapy. AIDS 18: 2145-2151.

Topp, S.M., Chipukuma, J.M., Chiko, M.M., Wamulume, C.S., Bolton-Moor, C. \& Reid, S.E. (2011) Optout provider initiated HIV testing and counselling in primary care outpatient clinics in Zambia. Bulletin of the World Health Organization 89: 328-335.

Topp, S.M., Li, M.S., Chipukuma, J.M., Chiko, M.M., Matongo, E., Bolton-Moore, C. \& Reid, S.E. (2012) Does provider-initiated counselling and testing (ITC) strengthening early diagnosis and treatment initiation? Results from an analysis of an urban cohort of HIV-positive patients in Lusaka, Zambia. Journal of the International AIDS Society 15: 17352.

Trepka, M.J., Fennie, K.P., Sheehan, D.M., Lutfi, K., Maddox, L. \& Lieb, S. (2014) late HIV diagnosis: differences by rural/urban residence, Florida, 2007-2011. AIDS Patient Care and STDs 28: 188-197.

UNAIDS (2012) UNAIDS Report on the Global AIDS Epidemic 2012

UNAIDS (2015) How HIV has changed everything. Fact Sheet 2015. UNAIDSWanyenze, R.K., Kamya, M.R., Fatch, R., Mayanja-Kizza, H., Baveewo, S., Sawires, S., Bangsberg, D.R., Coates, T. \& Hann, J.A. (2011) Missed opportunities for HIV testing and late-stage diagnosis among HIV-infected patients in Uganda. Public Library Sicence One 6: e21794

WHO (2015) Ten Facts on HIV/AIDS, World Health Organization, Geneva, Switzerland

Wong, K.H., Chan, K.C. \& Lee, S.S. (2004) Delayed progression to death and to AIDS in a Hong Kong cohort of patients with advanced HIV type 1 disease during the era of highly active antiretroviral therapy. Clinical Infectious Diseases 39: 853-860

Yeni, P.G., Hammer, S.M., Hirsch, M.S., Saag, M.S., Schechter, M., Carpenter, C.C., Fischl, M.A., Gatell, J.M., Gazzard, B.G., Jacobsen, D.M., Katzenstein, D.A., Montaner, J.S., Richman, D.D., Schooley, R.T., Thompson, M.A., Vella, S. \& Volberding, P.A. (2004) Treatment for adlt HIV infection: 2004 recommendations of the International AIDS Society, USA Panel. Journal of American Medical Association 292: 251-265. 